\title{
The Exploration and Research on the Open Autonomous Learning Model of Internet Plus Initiative
}

\author{
Yexing Pan \\ Jilin Agricultural Science and Technology College Jilin 132001, Jilin, China \\ 3600445850@qq.com
}

Keywords: Learning model; Autonomous learning; Llink

\begin{abstract}
This paper mainly discusses the independent learning model based on Internet plus initiative of college students. This learning model is an interactive link between teachers, students and knowledge in a virtual digital space. It is a link between teacher and student, teacher and knowledge, students and knowledge, students and students, knowledge and knowledge. In the meantime, the interactive relationship is the main element of the space, and the activation of these elements is the students' way of accepting knowledge, learning state and effect, and the method of teachers' virtual teaching. While the influence of space dynamics will also promote the birth of a new learning platform, students can also choose a more comfortable environment for learning to make this intuitive teaching environment well applied.
\end{abstract}

\section{Preface}

Twenty-first Century is the era of information explosion, people can not live without the Internet, computers and mobile phones which have penetrated into every corner of people's life, online office, online office, learning, conference, entertainment, games, chat, search, online banking, electronic payment, GPS positioning, and so on, to bring people a very rich and colorful life.

For a group of freshmen who are the most receptive to new things, college students are quick to accept new things and highly adaptable. With the help of the Internet and the new learning electronic equipment, in the Internet + open virtual reality space, students can gather knowledge and entertainment on an integrated network to excavate huge amounts of data and fun.

\section{Learning Model of College Students at Home and Abroad}

The most advanced mobile science in China was put forward in 2000, the researchers began to study the theory of autonomous learning from then on. In 2001, the Ministry of Education approved the first laboratory of autonomous learning in the laboratory of the modern education center of Peking University, which led the Tsinghua University and Beijing Normal University to carry out research on autonomous learning projects. In 2006, the mobile Internet information platform and SMS platform provided educational resources, technological innovation and other educational services to the recipient.

Wireless Andrew of Carnegie Mellon University started a series of mobile teaching practice projects in 1994, achieving remarkable results in a period of time. The supplier provided e-Learning and extended it to the m-Learning field, and quickly was launched into the market, which became the innovation education of the industry organization. The research of mobile equipment abroad is also early. The Alan Kay research group of American computer scientist put forward the concept of Dynabook in the PARC study (portable computing with the mobile function of the battery, which configures a variety of software. ${ }^{[1]}$ " In order to provide a good service platform for the learners, the joint Palm company has a program named Palm Education Pioneers Project (the PDA and computer of 
the company). Later, with the continuous promotion of network computing and mobile communication $2 \mathrm{G}, 3 \mathrm{G}, 4 \mathrm{G}$ technology, the market is out of the market. Many powerful mobile devices are now available

According to the latest statistics in July 2017, China has 1 billion 304 million mobile phone users, nearly $90 \%$ of whom use mobile phones, ranking the first in the world, and 646 million of them are 4G users. As of June 2016, there were 710 million Internet users in China, and 656 million of users using mobile Internet access, and the number of users using mobile Internet has increased to $92.5 \%{ }^{[2]}$.

According to the "report on the status quo of independent learning in China" published by Skillsoft in 2015, the feasibility, use and challenges of autonomous learning in China are analyzed. 95\% of the respondents said that self-study benefited them, and $74 \%$ believed that autonomous learning could help them acquire new knowledge and new skills. 54\% of the users expressed their preference for the content of self-study. Now the number of mobile phone users in China is close to 1 billion 300 million, that is, nearly $90 \%$ of people are using mobile phones. The data of 2013 summer homework which was conducted by Baidu showed that $32 \%$ of students were asking questions by mobile phones, $200 \%$ higher than last year, and the number of mobile phone questions in 2014 is expected to exceed $60 \%$ and will increase year by year. There are about 37 million 420 thousand college students in China in 2016, about 37 million 420 thousand college students in various colleges and universities in China, about 37 million 950 thousand college students in various colleges and universities in $2017^{[3-4]}$. From the survey of Baidu, it can be seen that the use of autonomous learning has increased year by year, and the other related learning type APP is similar. Nowadays, the popularity of mobile Internet is more conducive to the development of autonomous learning, and has created an interconnected platform for autonomous learning, and the potential of autonomous learning is huge(Fig. 1 Each year Chinese netizens refer to the graph).

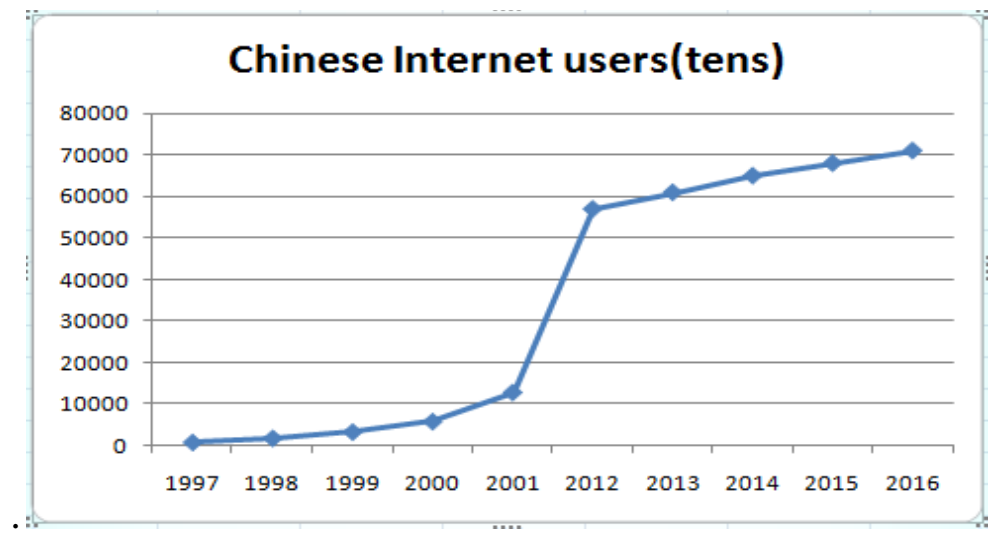

Figure 1. Finite Each year Chinese netizens refer to the graph

\section{The Multidimensional Analysis of the Open Autonomous Learning Model with the Guidance of Internet Plus Initiative}

Characteristics of Autonomous Learning Model. Reproduction of simulated learning scenarios: learners break the restrictions of time and space, they can study joyfully at any time and anywhere.Large data brings resources sharing learning and enjoyment: using the Internet platform, taking advantage of various mobile terminals for selective learning, enjoying the sharing of resources, and also having pleasant interactive learning.The upgrading of technology promotes the growing population of learners: the organic structure of mobile devices and Internet provides learners with a wide learning space. And the trend of this kind of learning is growing.

Factors Restricting the Model of Autonomous Learning. There are also some shortcomings in autonomous learning. The first one is the limitation of knowledge field. The content of knowledge is 
different from the same subject. Second, mobile devices are affected by external factors, such as the main storage capacity, the disturbance of the external environment, and the network bandwidth, which cause the low emotion in the learning process. Learners' learning efficiency is low, learning content is limited, and the evaluation of learning effect is more difficult.

The Group Analysis of Autonomous Learning Model. The first is that the learning group is limited by age, geography and time, and the demand is uncertain. The knowledge domain of learning is uncertain $^{[5]}$. Therefore, users, potential users, and peripheral users are three basic groups of users in the outer circle, but the classification of the 3 groups is not fixed, but in constant conversion and addition according to the function of the system and extension. Therefore, we should choose local diffusion method and small range location in user group processing.

The Research on Independent Learning Model Equipment. The equipment that supports random autonomous learning is called autonomous learning equipment. With the rapid development of science and technology, the learning equipment is constantly changing the birthday crescent. At the same time, various new learning products have emerged as the time requires. It is a bridge between the learners and the learning environment to communicate with each other. In the process of learning, it has its cognitive and logical judgment and storage function, and it is easy to carry and carry on the infinite network data transmission without the limitation of place and time.

Nowadays, there are various of types of learning equipment for college students, such as smart phones, IPD, tablet computers, learning dictionaries, etc. Because of the wide coverage of modern mobile communication, mobile phone technology is also very mature, large screen, high resolution, good sound quality, light volume, unimpeded 4G network, 100 megabytes bandwidth, easy access to web pages and video, so the mobile phone is the preferred device for students.

\section{The Analysis of the Results of Multi-style Questionnaire}

We can discuss the students' acceptance of autonomous learning through the questionnaire, on their the specific requirements of the mobile devices that they uses, the requirements of learning resources, and the factors that affect the self-learning factors of college students.

The study was conducted by the students of Agriculture Science And Technology College, which were investigated by the PPS sampling survey method. The subjects were major, sophomore, junior and senior students, including electronic information science and technology, computing science and technology, network engineering, electrical and automation, chemistry, English, gardening, A total of 74 students, including Chinese medicine, animal medicine, biotechnology and accounting, were sampled. The following four aspects are intercepted to analyze college students' autonomous learning habits: one affects college students' autonomous learning factors (Fig. 2-a); two is college students' demand for autonomous learning resources (Fig. 2-b); three is the choice of mobile devices to influence learning efficiency analysis (Fig. 2-c); four is the purpose of students' use of autonomous learning (Fig. 2-d).

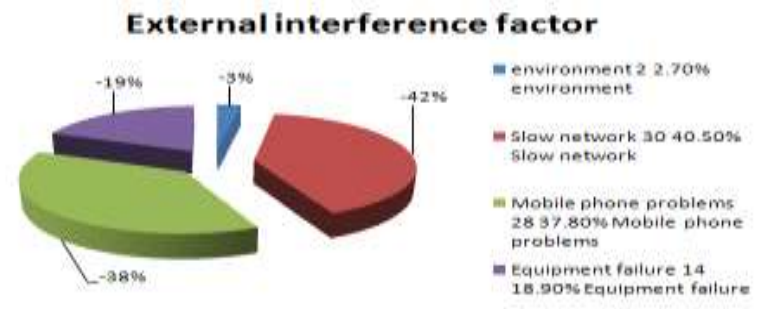

Figure 2-a. Finite

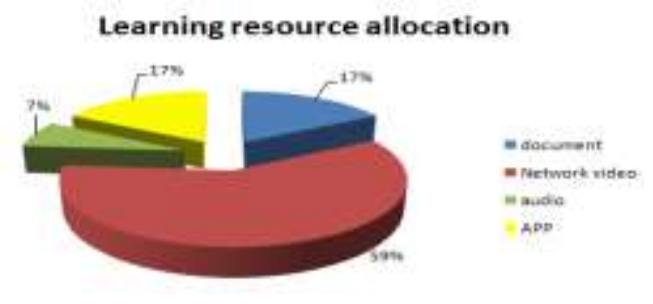

Figure 2-b. Finite 


\section{Choose mobile learning goals}

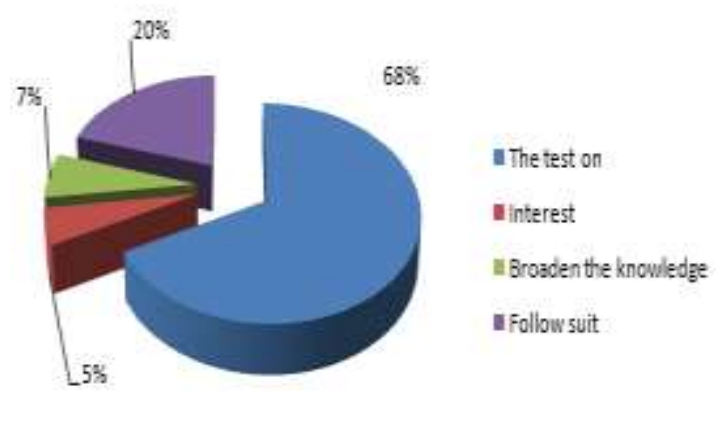

Figure 2-c. Finite

\section{Distribution using mobile devices}

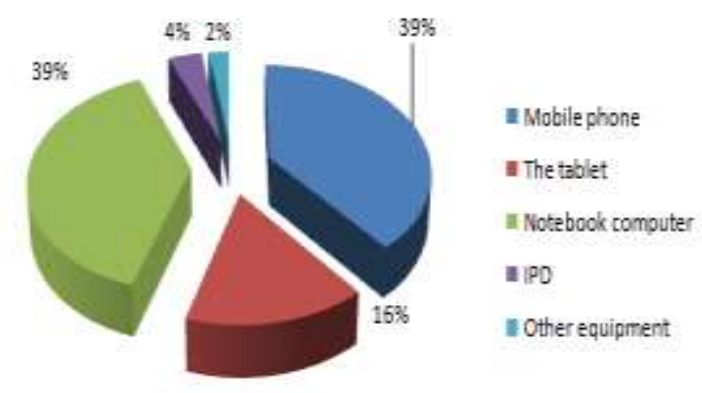

Figure 2-d. Finite

An Analysis of the Factors Affecting the Autonomous Learning of College Students. In the way of learning, college students generally use Internet to search engines and borrowing books or online video teaching, so $40 \%$ students think that the slow speed of the Internet is the main factor; and the $38 \%$ students consider the mobile phone problem (the screen is small, the quality of the screen causes visual fatigue), and $19 \%$ students think that the use of mobile devices failure (memory is small or equipment outdated)will affect learning. Only 3\% of students hold the belief that the external environment is also affected. At the same time, the habit of independent learning is different among the students of different majors. Most majors use the highest proportion of vocabulary translation classes. For the students of liberal arts, the proportion of APP and borrowing books is large, and the students of science and engineering specializes in the use of professional technical tools (video teaching and software download). ${ }^{[6-8]}$ The effect is different from day to day, because the emphasis is different, but the students of science and engineering are relatively efficient, because the students of science and engineering have a higher concentration.

Freshmen and sophomores choose to do more online translation and audio teaching, because they have to take part in CET-4\&CET6, and their autonomous learning helps to listen, speak and read, and the most obvious is vocabulary translation. The training and learning of the section mainly examines the ability to solve problems independently, so they will use all the time to learn, and they tend to study independently (using PC terminal to choose video) and solve problems in time. At this time, they do not focus on the examination, but focus on solving the problem.

An Analysis of College Students' Demand for Autonomous Learning Resources. According to the data, it can be found that college students generally use Internet search engines and borrow books or online video teaching, 59\% students choose network video teaching, $17 \%$ students search engines and borrowing books through Internet, 17\% use APP to learn, 7\% students use walking time to listen to audio, but these are not absolute, like watching online video, and with relevant learning materials.

The Analysis of the Learning Efficiency that was Influenced by the Selection of Mobile Devices. In the questionnaire, each student has mobile phone according to own family conditions, 39\% students choose the mobile phones and notebook computers, $19 \%$ students choose tablet computer, and 2\% choose other devices. The first machine can be studied at anytime and anywhere, but the students who are using mobile phones, notebook computers, and other social software such as WeChat or QQ, are easy to distract their attention which my cause the problem of lacking their concentration. APPs of learning types can not meet the requirements of students' communicating in their daily lives and with teachers. At the same time, the learning software for some practical and strong professional learning 
can not meet the actual needs of the students, and the efficiency of autonomous learning is generally considered not high.

An Analysis of the Purpose of Autonomous Learning. From the data of the above analysis, it can be concluded that the main use of mobile applications for college students is to deal with the exam. $64 \%$ of application is to deal with the exam, followed by $5 \%$ of interests, $7 \%$ of widening knowledge, and only $20 \%$ for the application of the casual entertainment and the edification function. Music APP is related. The increase in the frequency of college students occurs mainly in the case of problems or before the exam, and $47.52 \%$ students will also use APP to learn when they meet some of the boring lectures or activities of which is up to $64 \%$. Thus, it can be seen that the use of mobile devices for college students is mainly for the use of the examination, which provides a development direction for the designers of developing APPs of learning types.

The Analysis of other Factors. With the purpose of Fully investigating the problems and requirements of College Students' transfer learning. We take fully consideration from the perspective of users through questionnaires. For example, to increase the attraction of the students for the learning system, and to add the catering telephone and address, the page is more convenient, the UI is more exquisite, and the user can greatly improve the use efficiency. Therefore, we can create a more suitable learning platform for the vast number of users from the perspective of users.

\section{Problems in the Open Learning Model}

Due to the limitations of mobile devices and the current trend of educational reform, the promotion of autonomous learning is lagging behind. And today's various manufacturers and education and training institutions have been involved, because they have a strong backing and strong strength of the R \& D team, so the current autonomous learning equipment and functions are limited to these manufacturers and education and training institutions.

This open way of learning has changed the traditional way to acquire knowledge and interchangeably in space. It not only improves the students' interest in learning, but also improves the professional level of the teachers. At the same time, it also promotes the optimization of the online resources under the line of the educational institutions. The key is to drive the development of the third party electronic industry. But there is still a lot of problems in the study of autonomous learning. Students' own learning efficiency, hardware updates, etc., but with the reduction of the future wireless mobile equipment and communication costs, the improvement of hardware and the continuous improvement of the software platform, a large number of service providers have been used to promote it. It is believed that in the near future, autonomous learning will soon be extended to various institutions and other educational institutions.

\section{References}

[1] Liu Jianshe, Li Qing, Liu Jinmei. Current Research on Autonomous Learning: [J]. Audio-visual Education Research2007 (7) .21-25

[2] Li Yushun, Wang Xiaochen etc. Autonomous Learning Development at Home and Abroad: Status Quo Analysis and National Development Proposals. September 27, 2008 183-189 Seventh International Forum on Educational Technology

[3] Li Xinfu, Wei Xiangyun, Guangxi. Higher Vocational Colleges, Constructing an Autonomous Learning Mechanism to Study Consumption Guide. 2015(8)

[4] Yang Qiufen "Elliptical Learning Track" Mode of Autonomous Learning of Mobile Phone: Discussion on China's Electric Power Education.2015（8）

[5] Fang Haiguang, Wang Hongyun, Huang Ronghuai, Autonomic Learning System Environment Roadmap [J]. Modern Educational Technology,2011.21 
[6] Wang Xiaodong. System Learning Based on Mobile Short Message Service [J]. Chinese Audio-visual Education.2007.

[7] Li Xiaoli, Wang Xiaojun. Autonomous Learning Mode and System Architecture Design [J]. Journal of Beijing University of Posts and Telecommunications,2007

[8] Li Xuhong. Yangtze University "Palm Campus" APP System Development and Operation Research [J]. Entrepreneurship Research,2014.7 